\title{
INDIVIDUAL DIFFERENCES: ROLE OF PARENTS, SOCIETY AND TEACHERS
}

\author{
*Dr. Bhawna
}

\begin{abstract}
This paper explores the concept of individual differences particularly in educational settings. First of all what is the meaning of Individual difference and why it occur in educational settings. First of all what is Individual differences?

"Variations or deviations from the average of the group, with respect to the mental or physical characters occurring in the individual member of the group are individual differences."

This paper also discussed the measured and importance of individual differences fir the benefit of the masses particularly the students community.
\end{abstract}

Keywords: Individual Difference, Psychology, Educational, Society, Parents, Teachers.

\section{Introduction}

It is often said that no two individuals are exact duplicates; they differ from each other in some way or the other. Hence the job of the psychologists is to identify and understand this uniqueness in individuals. Such a similarity or difference between persons reveals individual differences. It happens in our day to day life when we see people around us. A question comes to mind how and why people appear similar or different to each other? For example when we think about their physical appearance, we often ask ourselves why some people have dark or fair complexation, why some people are thin and why some people are fat. When we think about their psychological characteristics we often come across people who are talkative or less talkative.

The present lesson tries to answer all such queries which can bother us in our everyday life. In psychology these are called Individual differences referring to the extent and kind of variations or similarities among people on some of the important psychological aspects such as intelligence, personality, interest and aptitude.

Definition of Individual difference points out the reality of traits that distinguish Individual differences point out the reality of traits that distinguish individuals. For example, The Encyclopedia of Social Psychology (Baumeister \& Vohs, 2007) defines individual differences in terms of enduring psychological characteristics. The Sage Glossary of the Social and Behavioral Sciences (Sullivan, 2009) has a definition of Individual differences that is particularly geared to learning Individual differences in age related decline of the medial temporal lobe system have been observed in both humans and rodents.
(Gallanger et al., 1993; Bizon and Gallagher, 2005; Wilson et al., 2002)

\section{Meaning of Individual Difference}

Dissimilatory is Principle of nature. No two persons are alike. All the individuals differ from each other in many a respects. Children born of the same parents and the twins are not alike. This different psychology is linked with the study of individual differences. This change is seen in physical forms like in height, weight, color, complexion strength etc. Difference in intelligence achievement, interest, attitude, aptitude, learning habits, motor abilities, and skill .Each man has an intellectual capacity through which he gains experience and learning. Every person has the emotions of love, anger, fear and feelings of pleasure and pain. Every man has the need of independence, success and need for acceptance.

Skinner, C.E.:

"Today we think of individual differences as including any measurable aspect of the total personality".

Woodworth, R.S. and Marquis, D.G.:

"Individual differences are found in all psychological characteristics, physical mental abilities, and Knowledge, habit, personality and character traits."

Perhaps the first task of every teacher in a class should be to know and study individual differences among his pupils. Individual differences in bodily appearance and physique, habits and skills, interests and temperaments abilities and attainments have already been recognized.

According to Skinner, "Today we think of individual differences as including any measurable aspect of the total personality". It is clear from this

*Psychology Teacher, R.P.S. International School, Rewari.

Email: sangeety@gmail.com 
definition of individual differences that it comprehends every aspect of human personality which is in some manner measurable.

\section{Nature of Individual Differences}

It has been observed that if we collect information about people's characteristics from a long sample and examine the pattern of distribution. We find that a large majority of the people fall in the middle range while a small portion lies in extreme categories. Individual differences occur due to interaction of genetic and environmental factors. We inherit certain characteristics from our parents through genetic codes. The phenotype or expressed forms of our characteristics depend on contributions of the socio-cultural environment. This is the reason why we are not exactly like our parent's. We do same similarities with our parents in respect of many physical attributes like height, color of eyes, shape of nose etc. We also inherit certain cognitive, emotional and other characteristics from our parents like intellectual competence, love for sport, creativity etc. However, and our own characteristics develop largely by the support from the environment which inhabit.

\section{Causes of Individual Differences}

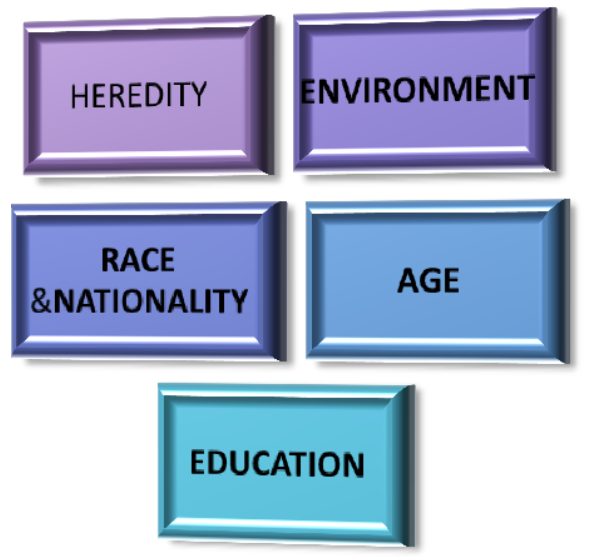

1. Heredity: Some heretical traits bring a change from one individual to other. An individual's height, size, shape and color of hair, shape of face, nose, hands and legs so to say the entire structure of the body is determined by his heretical qualities. Intellectual differences are also to a great extent influenced by hereditary factor. Body set ermined by his heretic great extent influenced by hereditary fact.

2. Environment: Environment brings individual differences in behavior, activities, attitude, and style of life characteristics. Environment does not refer only physical surroundings but also it refers the different types of people, society, their culture, customs, traditions, social heritage, ideas and ideals.
3. Race \& Nationality: Race and Nationality is one cause of individual difference .Indians are very peace loving, Chinese are cruel, Americans are very frank due to race and nationality.

4. Age: Age is another factor which is responsible in bringing individual differences. Learning ability and adjustment capacity naturally grow with age. When one grows in age can acquire better control over our emotions and better social responsibilities. When a child grows then this maturity and development goes side by side.

5. Education: Education is the most important factor which brings individual differences. There is a wide gap on the behaviors of educated and uneducated persons. All traits of human beings like social, emotional and intellectual are controlled and modifies through proper education.

This education brings a change in our attitude, behavior, appreciations, Personality. It is seen that uneducated persons are guided by their instinct and emotions whereas educated person are guided by their reasoning power.

\section{Conclusion}

Individual differences are a cornerstone subject area in modern psychology. In many ways it is the classic psychology that the general public refers to the psychology of the person - the psychological differences between people and their similarities. Plato stated more than 2000 years ago.

"No two persons are born exactly alike; but each differs from other in natural endowments, one being suited for one occupation and the other for another". Individual difference psychology examines how people are similar and how they differ in their thinking, feeling and behavior. No two people are like, yet no two people are unlike. So in the study of individual differences we strive to understand ways in which people are psychology similar and particularly what psycho-logic similar and particularly what psychological characteristics vary between people.

\section{References}

1. Ackerman, P.L. "Predicting individual differences in complex skill acquisition, Dynamics of ability determinants". Journal of Applied Psychology, 1992, 77, 598-614; 10,1037/0021-9010.77.5.598.

2. Holland, J.L. "A personality inventory employing occupational titles". Journal of Applied Psychology, 1958, 42, 336-342; 10.1037/h0047330. 
3. Holland, J.L. "Making Vocational Choices: A Theory of Carrers". Englewood Cliffs NJ: Prentice Hall, 1973.

4. Hertz, M.R. "The reliability of the Rorschach ink-blot-test". Journal of Applied Psychology, 1934, 18, 461-477; 10.1037/hOO71281
5. Agarwal, Nidhi; Pundir, Neelam. A Study of Personality Traits of B.Ed. Students. Learning Community - An International Journal of Educational and Social development, 2016, $7(2)$, pp 127-131; doi: 10.5958/2231458X.2016.00013.0.

6. Rathor, Rajat Satender; Sharma Shubham; Gupta Ruchika. "Agro-Biotechnology: A Tool for Reducing Hunger and Poverty". Globus: An International Journal of Management \& IT, 2017, 9(1), ISSN: 0975-721X, doi: $10.46360 /$ globus. 